\title{
Nephrolithiasis in gout: prevalence and characteristics of Brazilian patients
}

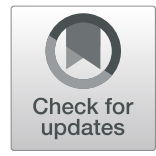

\author{
Leonardo Santos Hoff* (D, Claudia Goldenstein-Schainberg and Ricardo Fuller
}

\begin{abstract}
Background: The aims of this article were to assess the prevalence of nephrolithiasis and the factors associated with nephrolithiasis in Brazilian patients with primary gout.

Methods: One hundred twenty-three patients with primary gout were recruited from a tertiary referral hospital in São Paulo, Brazil. All patients underwent ultrasonography and had their clinical and laboratory characteristics assessed.

Results: One hundred fifteen (93.5\%) patients were male, with a mean age of $62.9 \pm 9.4$ years. Twenty-three (18.7\%) patients had asymptomatic nephrolithiasis (detected only by ultrasonography), 7 (6.0\%) had symptomatic nephrolithiasis (detected by ultrasonography and a positive clinical history), and 13 (10.0\%) had a history of kidney stones, but ultrasonography at evaluation did not show nephrolithiasis. Therefore, $35.0 \%$ of the patients had nephrolithiasis (detected either by ultrasonography and/or a positive clinical history). Nephrolithiasis was associated with male gender (43 [100\%] vs 72 [90\%], $p=0.049$ ), the use of potassium citrate (13 [30.2\%] vs $0, p<0.001)$ and the use of medications for diabetes (10 [23.3\%] vs 8 [10\%], $p=0.047)$ and dyslipidemia (15 [34.9\%] vs 10 [12.5\%], $p=0.003)$; benzbromarone had an inverse association with nephrolithiasis (21 [48.8\%] vs 55 [68.8\%], $p=0.030)$. In patients with and without nephrolithiasis, no differences were found in the laboratory and ultrasonography characteristics, including serum uric acid levels, urinary uric acid excretion and urine $\mathrm{pH}$.
\end{abstract}

Conclusions: The prevalence of nephrolithiasis in primary gout was $35.0 \%$, and $18.7 \%$ of the patients were asymptomatic. Nephrolithiasis was associated with male gender, diabetes and dyslipidemia. A positive history of nephrolithiasis probably biased the prescription of potassium citrate and benzbromarone.

Keywords: Nephrolithiasis, Urolithiasis, Gout, Metabolic syndrome, Brazil

\section{Introduction}

Gout is the most common form of inflammatory arthritis in men, and data from several countries suggest that it is becoming more prevalent $[1,2]$. Nephrolithiasis is a renal manifestation of gout that is reported in $14 \%$ of patients with gout in primary care [3] compared with only $5.6 \%$ of the general population [4]. This prevalence can be as high as $39 \%$ when imaging tools are used to actively screen for nephrolithiasis in asymptomatic gout patients [5, 6]. Nephrolithiasis can lead to pain, urinary tract infection or obstruction and chronic kidney disease [3]. The presence of nephrolithiasis has an impact when

\footnotetext{
* Correspondence: leonardo.hoff@hc.fm.usp.br

Division of Rheumatology, Hospital das Clínicas da Faculdade de Medicina da Universidade de São Paulo (HC-FMUSP), Av. Dr. Arnaldo 455, sala 3131, Sao Paulo 01246-903, Brazil
}

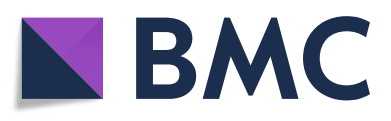

(c) The Author(s). 2019 Open Access This article is distributed under the terms of the Creative Commons Attribution 4.0 International License (http://creativecommons.org/licenses/by/4.0/), which permits unrestricted use, distribution, and reproduction in any medium, provided you give appropriate credit to the original author(s) and the source, provide a link to the Creative Commons license, and indicate if changes were made. The Creative Commons Public Domain Dedication waiver (http://creativecommons.org/publicdomain/zero/1.0/) applies to the data made available in this article, unless otherwise stated. choosing the appropriate medications for the management of gout.

The main factors associated with nephrolithiasis in patients with gout were described by Yu and Gutman [7]: low urine $\mathrm{pH}$, elevated serum uric acid levels and elevated daily urine urate excretion, leading to mainly uric acid stones. However, recent cross-sectional studies using validated diagnostic criteria for gout and imaging tools for diagnosing nephrolithiasis have revealed other associated factors $[5,6,8]$ and an increased prevalence of calcium oxalate stones [6]. To our knowledge, there are no studies from Brazil designed to assess the prevalence of nephrolithiasis and the factors associated with nephrolithiasis in patients with primary gout.

The primary aim of this study was to determine the prevalence of nephrolithiasis among Brazilian patients 
with primary gout admitted to our tertiary center clinic. The secondary aim was to identify the factors associated with nephrolithiasis in our population.

\section{Materials and methods Subjects}

From January 2000 to December 2006, 123 patients diagnosed with primary gout according to the American College of Rheumatology 1977 criteria [9] were consecutively recruited from our gout clinic, which is located in a tertiary referral hospital in São Paulo, Brazil.

\section{Methods}

The attending physician filled in a research protocol with the patients' clinical and laboratory characteristics, and the patients underwent ultrasonography; all data were then transcribed into a digital database. Therefore, this is a cross-sectional study. The study was performed in accordance with the ethical principles of the Declaration of Helsinki.

The following clinical parameters were assessed: gender, age, self-reported skin color/race, date of gout diagnosis, duration of disease, the presence of tophi, smoking status (past or present), alcohol use disorder (past or present), medications in use and history of nephrolithiasis. A positive history of nephrolithiasis was defined as the patient answering "yes" to the question "Have you ever had kidney stones either associated with pain and/or passage into the urine?"

The following laboratory data were assessed: serum creatinine, estimated glomerular filtration rate (using the Chronic Kidney Disease Epidemiology Collaboration [CKD-EPI] equation [10]), serum urea, serum uric acid (determined by the uricase method), clearance of uric acid, underexcretion of uric acid, urinary uric acid excretion over $24 \mathrm{~h}$, serum glucose, serum total cholesterol, serum triglycerides and urinalysis. Urine $\mathrm{pH}$ was assessed with a dipstick in a fresh urine sample. Underexcretion of uric acid was defined as a clearance of $<6$ $\mathrm{mL} / \mathrm{min}$. Lithiasis, cysts and indirect signs of chronic kidney disease were evaluated using a grey scale ultrasound imaging. The exam was performed by a random radiologist physician using a curvilinear probe with a transmit frequency of 2.5 to $6.0 \mathrm{MHz}$; kidneys were evaluated in multiple anatomic planes.

Statistical analysis: Shapiro-Wilk's test was used to test for normality. Continuous variables were compared using Student's t-test or the Mann-Whitney test as appropriate. Categorical variables were compared using the chi-squared test or Fisher's exact test as appropriate. A two-tailed $P$ value of $\leq 0.05$ was considered statistically significant. The Statistical Package for the Social Sciences (Windows version 16.0; SPSS Inc., Chicago, IL, US) was used for all the statistical analyses.

\section{Results}

Out of a total of 123 patients, 115 (93.5\%) were male, and $102(82.9 \%)$ were white, with a mean age of 62.9 years (standard deviation $-\mathrm{SD} \pm 9.4$ ). The onset of the disease occurred at $44.9 \pm 12,3$ years, and the duration of the disease was $18.2 \pm 10.5$ years. Most of the subjects had a history of alcohol use disorder 73.2\%) and smoking tobacco $(51.2 \%)$. The medications most often prescribed for gout were benzbromarone (61.8\%), nonsteroidal anti-inflammatory drugs (NSAIDs, 52.0\%), allopurinol (36.6\%), colchicine $(26.0 \%)$ and potassium citrate (10.6\%). Medications prescribed for comorbidities included antihypertensive medication (74.8\%), lipidlowering medication (20.3\%) and antidiabetic medication $(14.6 \%)$. One hundred and ten $(89.4 \%)$ of the patients were classified as having underexcretion of uric acid. Laboratory features included a mean serum creatinine of $1.34 \pm 0,55 \mathrm{mg} / \mathrm{dL}$, serum uric acid levels of $7.13 \pm 1.95$ $\mathrm{mg} / \mathrm{dL}$, uric acid clearance of $5.48 \pm 3.91 \mathrm{~mL} / \mathrm{min}$ and a urine $\mathrm{pH}$ of $5.79 \pm 0.83$. The patients' complete and detailed clinical and laboratory characteristics are shown in Table 1.

The prevalence of nephrolithiasis, as assessed either by clinical history or ultrasonography, is depicted in Table 2 and Table 3. Thirty (24.4\%) patients had detectable nephrolithiasis on ultrasonography, and 20 (16.3\%) reported a positive history of kidney stones, resulting in a total of $43(35.0 \%)$ patients with nephrolithiasis (detected by either ultrasonography and/or positive clinical history). Twenty-three (18.7\%) patients had asymptomatic nephrolithiasis (detected only on ultrasonography), 7 (6.0\%) had symptomatic nephrolithiasis (detected by ultrasonography and a positive clinical history), and 13 (10.0\%) had a positive history of kidney stones, but ultrasonography at evaluation did not show nephrolithiasis.

Comparisons between the patients with nephrolithiasis and those without nephrolithiasis are shown in Table 4 (clinical comparisons) and Table 5 (laboratory and ultrasonography comparisons). Patients with nephrolithiasis were more likely to be male ( 43 of 43 patients [100\%] vs 72 of 80 patients [90\%], $p=0.049$ ), to be taking potassium citrate (13 [30.2\%] vs $0, p<0.001)$ and to be taking medications for diabetes $(10$ [23.3\%] vs 8 [10\%], $p=$ $0.047)$ and dyslipidemia (15 [34.9\%] vs 10 [12.5\%], $p=$ $0.003)$. Patients with nephrolithiasis were less likely to be taking benzbromarone (21 [48.8\%] vs 55 [68.8\%], $p=$ $0.030)$. No statistically significant differences were found in the laboratory and ultrasonography characteristics, including serum uric acid levels, urinary uric acid excretion or urine $\mathrm{pH}$.

\section{Discussion}

The prevalence of nephrolithiasis in patients with primary gout in our population was $35.0 \%$, which is higher 
Table 1 Clinical and laboratory features of 123 Brazilian patients with primary gout

\begin{tabular}{|c|c|}
\hline & Value \\
\hline Male gender & $115(93.5 \%)$ \\
\hline \multicolumn{2}{|l|}{ Skin color/race } \\
\hline White & $102(82.9 \%)$ \\
\hline Brown or Black & $14(11.4 \%)$ \\
\hline Asian & $7(5.7 \%)$ \\
\hline Age (years) & $62.9 \pm 09.4$ \\
\hline Age at the onset of disease (years) & $44.9 \pm 12.3$ \\
\hline Duration of disease (years) & $18.2 \pm 10.5$ \\
\hline Tophi & 69 (56.1\%) \\
\hline Underexcretion of uric acid & $110(89.4 \%)$ \\
\hline Alcohol use disorder & $90(73.2 \%)$ \\
\hline Current & $23(18.7 \%)$ \\
\hline Past & $67(54.5 \%)$ \\
\hline Smoking history & $63(51.2 \%)$ \\
\hline Current & $10(8.1 \%)$ \\
\hline Past & $53(43.1 \%)$ \\
\hline \multicolumn{2}{|l|}{ Medication } \\
\hline Allopurinol & $45(36.6 \%)$ \\
\hline Benzbromarone & $76(61.8 \%)$ \\
\hline Potassium citrate & $13(10.6 \%)$ \\
\hline Colchicine & $32(26.0 \%)$ \\
\hline Glucocorticoids & $7(5.7 \%)$ \\
\hline NSAIDs & $64(52.0 \%)$ \\
\hline Antidiabetic medication & $18(14.6 \%)$ \\
\hline Antihypertensives & $92(74.8 \%)$ \\
\hline Lipid-lowering medication & $25(20.3 \%)$ \\
\hline Serum creatinine (mg/dL) & $1.34 \pm 0.55$ \\
\hline Serum urea $(\mathrm{mg} / \mathrm{dL})$ & $44.1 \pm 25.3$ \\
\hline eGFR - CKD EPI (mL/min/1.73 m²) & $63.9 \pm 21.7$ \\
\hline Serum uric acid levels (mg/dL) & $7.13 \pm 1.95$ \\
\hline Uric acid clearance (mL/min) & $5.48 \pm 3.91$ \\
\hline Uric acid clearance $<6 \mathrm{~mL} / \mathrm{min}$ & $85(69.1 \%)$ \\
\hline Urinary uric acid excretion (g/24 h) & $0.53 \pm 0.30$ \\
\hline Serum glucose (mg/dL) & $105.7 \pm 26.8$ \\
\hline Serum total cholesterol (mg/dL) & $205.4 \pm 49.4$ \\
\hline Serum triglyceride (mg/dL) & $231.4 \pm 399.6$ \\
\hline \multicolumn{2}{|l|}{ Urinalysis } \\
\hline $\mathrm{pH}$ & $5.79 \pm 0.83$ \\
\hline Pyuria (> 10 leukocytes/HPF) & $6(4.9 \%)$ \\
\hline Hematuria (> 3 erythrocytes/HPF) & $12(9.8 \%)$ \\
\hline Significant proteinuria & $5(4.1 \%)$ \\
\hline
\end{tabular}

Data are expressed as the total (\%) or the mean \pm SD $C K D$ - EPI Chronic Kidney Disease Epidemiology Collaboration equation eGFR estimated glomerular filtration rate HPF high-power field

NSAIDs nonsteroidal anti-inflammatory drugs than the prevalence observed in patients with gout in population-based studies (14.0\%) [3] or in the general population (5.6\%) [4]. The main reason for this high prevalence in our population is that the patients were actively screened for nephrolithiasis with an imaging tool: only $20(16.3 \%)$ patients reported a positive history of nephrolithiasis; however, ultrasonography identified 23 (19\%) asymptomatic patients. Wan et al. [8] and Alvarez-Nemegyei et al. [5] also described a high prevalence of nephrolithiasis (31.6 and 39.3\%, respectively) among patients with primary gout who underwent ultrasonography at tertiary centers. Shimizu et al. [6] found a prevalence of $33.9 \%$ in patients with primary gout assessed with computerized tomography (CT). A metaanalysis of epidemiological studies by Roughley et al. [3] and a study by $\mathrm{Yu}$ and Gutman [7] described that the prevalence of nephrolithiasis is much lower if it is selfreported (14 and 22.3\%, respectively). Another factor that may have contributed to this high prevalence is that these patients were assessed in a tertiary referral center, where patients with more severe gout were referred. A high prevalence of metabolic syndrome, which can be inferred by the proportion of subjects taking medications for hypertension, diabetes and dyslipidemia, may also have played a role because metabolic syndrome is an independent risk factor for the formation of kidney stones [11,12].

To our knowledge, there are no studies from Brazil designed to assess the prevalence of nephrolithiasis and the factors associated with nephrolithiasis in patients with primary gout. Azevedo et al. [13] described a small cohort of 48 patients with gout who were taking allopurinol, benzbromarone or both, and the self-reported prevalence of nephrolithiasis was $25 \%$. Hasegawa et al. [14] studied the prevalence of renal cysts detected by ultrasonography in patients with gout; the prevalence of nephrolithiasis was $21 \%$, and the presence of cysts was inversely related to nephrolithiasis. Souza et al. [15] compared the clinical and laboratory features of gout in men and women, and the self-reported prevalence of nephrolithiasis was 22.6 and $18.5 \%$, respectively. None of these studies analyzed the factors associated with nephrolithiasis in Brazilian subjects.

In the current study, patients with nephrolithiasis were more likely to be male and to be undergoing medical treatment for diabetes and dyslipidemia. The highest prevalence of nephrolithiasis in males and in patients with metabolic syndrome has already been described in the general population [12]. A positive history of nephrolithiasis probably biased the prescription of potassium citrate and benzbromarone. The classical main factors associated with nephrolithiasis in patients with gout described by $\mathrm{Yu}$ and Gutman [7] (low urine pH, elevated serum uric acid levels and elevated daily urine urate excretion) were not statistically significant in our 
Table 2 Ultrasonography findings plus the prevalence of nephrolithiasis

\begin{tabular}{ll}
\hline & $N=123$ \\
\hline Ultrasonography findings & 30 \\
Nephrolithiasis & $(24.4 \%)$ \\
& 46 \\
Cysts & $(37.4 \%)$ \\
& $10(8.1 \%)$ \\
Chronic kidney disease appearance & 20 \\
Positive history of nephrolithiasis & $(16.3 \%)$ \\
& 43 \\
Total prevalence of nephrolithiasis (ultrasound and/or & $(35.0 \%)$ \\
history) & \\
\hline Data are expressed as the total (\%) &
\end{tabular}

population, probably because these laboratory data were assessed in patients who were already taking medications that modify these laboratory parameters. Interestingly, Alvarez-Nemegyei et al. [5] found that a higher urinary $\mathrm{pH}$ was associated with nephrolithiasis, which can be explained by the fact that alkalinizing agents are prescribed more often for patients with nephrolithiasis. Other factors that have been associated with nephrolithiasis in patients with gout, including serum uric acid levels $\geq 10$ $\mathrm{mg} / \mathrm{dL}$ [8] and elevated serum creatinine and urea [6], were not observed in our population.

A complete urinary excretion profile and the composition of the calculi was not assessed in our sample; a recent study from Shimizu et al. [6] showed that only one third of the calculi from patients with gout were of pure uric acid, compared to more than two thirds observed in the classic study from $\mathrm{Yu}$ and Gutman [7]. This may be partially explained by the increasing prevalence of metabolic syndrome, a known risk factor for calcium oxalate stones $[11,12]$. However, further studies are necessary to confirm this shift in the composition of nephrolithiasis from patients with gout.

This study has several limitations. It was a crosssectional study including patients who were recruited from a tertiary referral center; therefore, they may have had more severe disease than patients from primary care facilities. All the data were collected and stored in a digital database in 2006; however, only in 2019 were these data analyzed and prepared for publication. Despite the potential shifts in diet, lifestyle and disease

Table 3 Positive history of nephrolithiasis vs ultrasonography

\begin{tabular}{llll}
\hline & \multicolumn{2}{l}{ Positive history of nephrolithiasis } & \\
\cline { 2 - 3 } & Yes & No & Total \\
\hline US with nephrolithiasis & 70 & 103 & \\
US without nephrolithiasis & 13 & 23 & 30 \\
\hline
\end{tabular}

US ultrasonography
Table 4 Comparison between patients with and without nephrolithiasis (clinical characteristics)

\begin{tabular}{|c|c|c|c|}
\hline & $\begin{array}{l}\text { Nephrolithiasis } \\
(N=43)\end{array}$ & $\begin{array}{l}\text { Without } \\
\text { Nephrolithiasis } \\
(N=80)\end{array}$ & $P$ Value \\
\hline Male gender & $43(100 \%)$ & $72(90.0 \%)$ & 0.049 \\
\hline Skin color/race: white & 37 (86.0\%) & 65 (81.2\%) & 0.500 \\
\hline Age (years) & $61.3 \pm 9.7$ & $63.8 \pm 9.3$ & 0.161 \\
\hline $\begin{array}{l}\text { Age of onset of disease } \\
\text { (years) }\end{array}$ & $42.3 \pm 11.4$ & $46.4 \pm 12.7$ & 0.080 \\
\hline $\begin{array}{l}\text { Duration of disease } \\
\text { (years) }\end{array}$ & $19.0 \pm 10.8$ & $17.8 \pm 10.4$ & 0.502 \\
\hline$<5$ years & $1(9.1 \%)^{*}$ & $10(90.9 \%)^{*}$ & $0.168+$ \\
\hline $5-15$ years & $19(38.0 \%)^{*}$ & $31(62.0 \%)^{*}$ & - \\
\hline$>15$ years & $23(37.1 \%)^{*}$ & $39(62.9 \%)^{*}$ & - \\
\hline Tophi & $24(55.8 \%)$ & $45(56.2 \%)$ & 0.963 \\
\hline $\begin{array}{l}\text { Underexcretion of uric } \\
\text { acid }\end{array}$ & 38 (88.4\%) & $72(91.4 \%)$ & 0.624 \\
\hline Alcohol use disorder & $36(83.7 \%)$ & $54(67.5 \%)$ & 0.053 \\
\hline Current & 9 (20.9\%) & $14(17.5 \%)$ & 0.642 \\
\hline Past & 27 (62.8\%) & $40(50.0 \%)$ & 0.174 \\
\hline Smoking history & $25(58.1 \%)$ & $38(47.5 \%)$ & 0.260 \\
\hline Current & $2(4.7 \%)$ & $8(10.0 \%)$ & 0.491 \\
\hline Past & $23(53.5 \%)$ & $30(37.5 \%)$ & 0.088 \\
\hline \multicolumn{4}{|l|}{ Medication } \\
\hline Allopurinol & 19 (44.2\%) & $26(32.5 \%)$ & 0.199 \\
\hline Benzbromarone & $21(48.8 \%)$ & $55(68.8 \%)$ & 0.030 \\
\hline Potassium citrate & $13(30.2 \%)$ & Zero & $\begin{array}{l}< \\
0.001\end{array}$ \\
\hline Colchicine & 15 (34.9\%) & $17(21.2 \%)$ & 0.100 \\
\hline Glucocorticoids & $2(4.7 \%)$ & $5(6.2 \%)$ & 1.000 \\
\hline NSAIDs & $23(53.5 \%)$ & $41(51.2 \%)$ & 0.813 \\
\hline $\begin{array}{l}\text { Antidiabetic } \\
\text { medication }\end{array}$ & $10(23.3 \%)$ & $8(10.0 \%)$ & 0.047 \\
\hline Antihypertensives & $34(79.1 \%)$ & $58(72.5 \%)$ & 0.424 \\
\hline $\begin{array}{l}\text { Lipid-lowering } \\
\text { medication }\end{array}$ & 15 (34.9\%) & $10(12.5 \%)$ & 0.003 \\
\hline
\end{tabular}

Data are expressed as the total (\%) or the mean \pm SD, unless otherwise stated NSAIDs nonsteroidal anti-inflammatory drugs

* Percentage for each subgroup

$+p$ value for the comparison among the three disease duration subgroups

prevalence that may have occurred in Brazil from 2006 to 2019, these results may still be representative of our population. Our patients were assessed with ultrasonography, which is less sensitive than $\mathrm{CT}$ for the diagnosis of nephrolithiasis [16], and ultrasonography cannot be used to infer the composition of kidney stones. However, ultrasonography is less expensive than CT, does not involve exposure to ionizing radiation [17] and is considered by the European Association of Urology to be a primary diagnostic imaging tool [18]. Urine $\mathrm{pH}$ was 
Table 5 Comparison between patients with and without nephrolithiasis (laboratory and ultrasonography characteristics)

\begin{tabular}{|c|c|c|c|}
\hline & Nephrolithiasis $(N=43)$ & Without Nephrolithiasis $(N=80)$ & $P$ Value \\
\hline Serum creatinine (mg/dL) & $1.26 \pm 0.42$ & $1.38 \pm 0.61$ & 0.507 \\
\hline Serum urea (mg/dL) & $41.7 \pm 22.2$ & $45.4 \pm 26.8$ & 0.387 \\
\hline eGFR - CKD EPI (mL/min/1.73 m²) & $68.0 \pm 22.3$ & $61.6 \pm 21.1$ & 0.116 \\
\hline Serum uric acid levels (mg/dL) & $7.20 \pm 2.11$ & $7.09 \pm 1.87$ & 0.785 \\
\hline Uric acid clearance (mL/min) & $5.25 \pm 3.38$ & $5.61 \pm 4.18$ & 0.518 \\
\hline Uric acid clearance $<6 \mathrm{~mL} / \mathrm{min}$ & $32(74.4 \%)$ & $53(67.1 \%)$ & 0.400 \\
\hline Urinary uric acid excretion (g/24 h) & $0.55 \pm 0.33$ & $0.52 \pm 0.28$ & 0.879 \\
\hline Serum glucose (mg/dL) & $111.3 \pm 36.1$ & $102.6 \pm 19.8$ & 0.256 \\
\hline Serum total cholesterol (mg/dL) & $207.1 \pm 57.7$ & $204.5 \pm 44.8$ & 0.924 \\
\hline Serum triglycerides (mg/dL) & $307.8 \pm 639.3$ & $190.4 \pm 156.3$ & 0.627 \\
\hline \multicolumn{4}{|l|}{ Urinalysis } \\
\hline $\mathrm{pH}$ & $5.87 \pm 0.80$ & $5.75 \pm 0.85$ & 0.383 \\
\hline Pyuria (> 10 leukocytes/HPF) & $2(4.7 \%)$ & $4(5.0 \%)$ & 1.000 \\
\hline Hematuria (> 3 erythrocytes/HPF) & $7(16.3 \%)$ & $5(6.2 \%)$ & 0.074 \\
\hline Significant proteinuria & $1(2.3 \%)$ & $4(5.0 \%)$ & 0.657 \\
\hline \multicolumn{4}{|l|}{ Ultrasonography } \\
\hline Cysts & 20 (46.5\%) & $26(32.5 \%)$ & 0.126 \\
\hline CKD appearance & $3(7.0 \%)$ & 7 (8.8\%) & 1.000 \\
\hline
\end{tabular}

Data are expressed as the total (\%) or the mean \pm SD

$C K D$ Chronic kidney disease

CKD - EPI Chronic Kidney Disease Epidemiology Collaboration equation

eGFR estimated glomerular filtration rate

HPF high-power field

assessed with a dipstick, which has a good statistical correlation with the gold standard method - a pH meter [19]. Nevertheless, dipstick is more inaccurate than a $\mathrm{pH}$ meter, especially in higher $\mathrm{pH}$ values [19]; for that reason, our findings of the $\mathrm{pH}$ in this population sample should be interpreted with caution.

\section{Conclusion}

The prevalence of nephrolithiasis in primary gout is high, and many patients are asymptomatic. Therefore, patients should be screened for this condition either with ultrasonography or CT. Identifying patients with lithiasis is important for preventing complications associated with this pathologic process and to determine the most appropriate therapy for gout. In the current study of Brazilian subjects, nephrolithiasis was associated with male gender and treatments for diabetes and dyslipidemia.

\section{Acknowledgments}

The authors thank all the patients who participated in this study.

\section{Author's contributions}

LSH contributed with the conception, design of the work, analysis and interpretation of data and have drafted the manuscript. CGS contributed with the conception, design of the work, and substantively revised the manuscript. RF contributed with the conception, design of the work, acquisition, analysis and interpretation of data and have drafted the manuscript. All authors read and approved the final manuscript.

\section{Funding}

This study received no funding.

Availability of data and materials

The primary data referent to the present study is available upon request to the corresponding author.

Ethics approval and consent to participate

This study was approved by the hospital ethics committee (protocol 3.377.422).

\section{Consent for publication}

All authors are aware of the full content of the manuscript and provided consent for the submission to Advances in Rheumatology.

\section{Competing interests}

The authors have declared no conflicts of interest.

Received: 15 August 2019 Accepted: 23 December 2019

Published online: 31 December 2019

\section{References}

1. Roddy E, Choi HK. Epidemiology of gout. Rheum Dis Clin N Am. 2014;40(2): 155-75. https://doi.org/10.1016/j.rdc.2014.01.001.

2. Smith $E$, Hoy $D$, Cross $M$, et al. The global burden of gout: estimates from the global burden of disease 2010 study. Ann Rheum Dis. 2014;73(8):14706. https://doi.org/10.1136/annrheumdis-2013-204647.

3. Roughley MJ, Belcher J, Mallen CD, Roddy E. Gout and risk of chronic kidney disease and nephrolithiasis: meta-analysis of observational studies. Arthritis Res Ther. 2015;17(1):90. https://doi.org/10.1186/s13075-015-0610-9. 
4. Romero V, Akpinar H, Assimos DG. Kidney stones: a global picture of prevalence, incidence, and associated risk factors. Rev Urol. 2010;12(2-3): e86-96.

5. Alvarez-Nemegyei J, Medina-Escobedo M, Villanueva-Jorge S, VazquezMellado J. Prevalence and risk factors for Urolithiasis in primary gout: is a reappraisal needed? J Rheumatol. 2005;32(11):2189-91.

6. Shimizu T, Kitada H, Umeyama M, Hori H, Takasaki N. Novel evaluation of nephrolithiasis as a complication of gout: a cross-sectional study using helical computerized tomography. J Urol. 2013;189(5):1747-52. https://doi. org/10.1016/j.juro.2012.11.076.

7. Yü T, Gutman AB. Uric acid nephrolithiasis in gout Predisposing factors. Ann Intern Med. 1967;67(6):1133-48

8. Wan K, Liu C, Ko M, Lee W, Huang C. Nephrolithiasis among male patients with newly diagnosed gout. Hong Kong Med J. 2016;22(6):534-7. https:// doi.org/10.12809/hkmj154694.

9. Wallace SL, Robinson H, Masi AT, Decker JL, McCarty DJYT. Preliminary criteria for the classification of the acute arthritis of primary gout. Arthritis Rheum. 1977;20(3):895-900.

10. Levey AS, Stevens LA, Schmid CH, et al. A new equation to estimate glomerular filtration rate. Ann Intern Med. 2009;150(9):604-12.

11. Curhan GC. Epidemiology of stone disease. Urol Clin North Am. 2007;34(3): 287-93.

12. Scales CD, Smith AC, Hanley JM, Saigal CS. Prevalence of kidney stones in the United States. Eur Urol. 2012;62(1):160-5. https://doi.org/10.1016/j. eururo.2012.03.052.

13. Azevedo VF, Buiar PG, Giovanella LH, Severo CR, Carvalho M. Allopurinol, benzbromarone, or a combination in treating patients with gout: analysis of a series of outpatients. Int J Rheumatol. 2014:263720. https://doi.org/10. 1155/2014/263720.

14. Hasegawa EM, Fuller R, Chammas MC, De Mello FM, GoldensteinSchainberg C. Increased prevalence of simple renal cysts in patients with gout. Rheumatol Int. 2013;33(2):413-6. https://doi.org/10.1007/s00296-0122380-x.

15. De Souza AWS, Fernandes V, Ferrari AJL. Female gout: clinical and laboratory features. J Rheumatol. 2005;32(11):2186-8.

16. Smith-Bindman R, Aubin C, Bailitz J, et al. Ultrasonography versus computed tomography for suspected nephrolithiasis. N Engl J Med. 2014;371(12):110010. https://doi.org/10.1056/NEJMoa1404446.

17. Brisbane W, Bailey MR, Sorensen MD. An overview of kidney stone imaging techniques. Nat Rev Urol. 2016;13(11):654-62. https://doi.org/10.1038/nrurol. 2016.154.

18. Türk C, Petřik A, Sarica K, et al. EAU guidelines on diagnosis and conservative Management of Urolithiasis. Eur Urol. 2016;69(3):468-74. https://doi.org/10.1016/j.eururo.2015.07.040.

19. Kwong T, Robinson C, Spencer D, et al. Accuracy of urine pH testing in a regional metabolic renal clinic: is the dipstick accurate enough? Urolithiasis. 2013;41(2):129-32. https://doi.org/10.1007/s00240-013-0546-y.

\section{Publisher's Note}

Springer Nature remains neutral with regard to jurisdictional claims in published maps and institutional affiliations.

Ready to submit your research? Choose BMC and benefit from:

- fast, convenient online submission

- thorough peer review by experienced researchers in your field

- rapid publication on acceptance

- support for research data, including large and complex data types

- gold Open Access which fosters wider collaboration and increased citations

- maximum visibility for your research: over $100 \mathrm{M}$ website views per year

At $\mathrm{BMC}$, research is always in progress.

Learn more biomedcentral.com/submissions 